\title{
Determination of the development level of information and telecommunication networks within the regions of Siberian Federal District
}

\author{
Maria Chuvashova ${ }^{1, *}$, Gleb Druzhinin ${ }^{1}$ and Alena Gorbacheva ${ }^{2}$ \\ ${ }^{1}$ Irkutsk State University, 664003 Irkutsk, Russia \\ ${ }^{2}$ Reshetnev Siberian State University of Science and Technology, 660031 Krasnoyarsk, Russia
}

\begin{abstract}
According to the scientific papers of the Russian scientists, the parameters for assessing the quality of economic space are population density, spatial connectivity and location of production. The parameter of the spatial connectivity is considered. In most of the Russian scientific papers, the term "the spatial connectivity" is determined by the level of transport networks development. In most Russian scientific papers when forming models for assessing the spatial connectivity of regions, the issue of territorial connectivity by information and telecommunication networks is not investigated. The papers analyses the main characteristics of the concept of regional space connectivity and its properties. An econometric analysis of statistical data on indicators characterizing information and telecommunication networks for each of the regions of the Siberian Federal District has been carried out. The mathematical model and an algorithm for automating the procedure for calculating statistical indicators in the Python language in the Spyder programming environment were proposed for calculating the indicators. The most and least developed regions within developing the information and telecommunication networks have been identified. The resulting mechanism for determining the level of development of information and telecommunication networks will be useful for monitoring the territory and drawing up a passport of an each region.
\end{abstract}

\section{Introduction Research methodology}

Sustainable development of the region is a complex process leading to solving the problems of the population at the regional level, to improving the living sstandard by achieving a balance of socio-economic and environmental development, which carried out on the basis of the efficient use of the entire resource potential of the region. The sustainable development of regions depends on the economic space quality. Also the sustainable development of the territory is directly achieved by improving the quality of the economic space. Three parameters are used to assess the quality of the economic space in the Russian regional science: the spatial connectivity, the density and location of production [1].

\footnotetext{
* Corresponding author: dersaturn06@gmail.com
} 
The relevance of this study of the spatial connectivity is associated with the functioning of a comprehensive scientific and technological program for the development of Russia "The Spatial Connectivity of the territories of the Russian Federation" and "Digital economy of the Russian Federation" for the period from 2018 to 2024. The spatial connectivity involves the solution of two strategic tasks: strengthening the political position of Russia in the world and overcoming regional socio-economic imbalances.

Sociological studies confirm the high rates of development of the information and telecommunication networks in the Russian Federation. The Internet audience in Russia has grown from 14.6 million people (i.e. $12 \%$ of the population of the Russian Federation) to 60.8 million people from 2003 to 2019 (i.e. $73 \%$ of the population of the Russian Federation is over 18 years old) [2].

Connectivity as a property of regional space determines the spatial distribution of resources and the achievement of an economic effect from their use. The spatial connectivity determines the unity of the economic space of the Russian Federation, and also affects the effectiveness of the implementation of an integrated economic policy in the presence of territorial diversity.

The state development programs in Russia are formed taking into account the transport corridors. However, transport networks are not the only means of measuring the spatial connectivity of territories. Their location, length, accessibility and location features determine the development of an economic activity and also determine the architecture of the spatial arrangement of objects in the region [3].

The insufficient knowledge of the properties of economic space in the context of the problem of ensuring regional development, taking into account the resources available to the territories, as well as the existing mechanisms of management, actualizes the need for such research. Studying the properties of the spatial connectivity of economic space can provide significant progress in solving the problem of asymmetry of regional development, which manifests itself in a number of contradictions. These contradictions are connected with according to such criteria as settlement (the problem of "urban-rural"), the allocation of capital and the movement of migration flows (the problem of the "center-periphery", "metropolis-province"), the location of production (the problem of disproportion between geographical areas, for example North-South), etc.[3,4].

The economic space of the region is largely determined by the degree of development of both the resource base of the region (including the concentration of capital, natural resources, intellectual capital, the level of development of engineering and social infrastructure, etc.), and management actions.

The connectivity of the regional economic space (both intra- and interregional) largely depends on the regional and federal economic policy. Thus, a well-built and balanced policy that takes into account the interconnectedness of the economic space, global and national trends in economic activity is intended to contribute to a more active involvement of Russian regions in economic activity [2].

The study of the level of information and telecommunication networks of spatial connectivity was chosen by the authors of the Siberian Federal District, because this district has an unbalanced structure of the economy from a geographical point of view. On the one hand, it includes the northern territories, where large resource bases and cities are located, on the other, vast uninhabited territories and densely populated areas in the south. The economic space of the Siberian Federal District belongs to the type of polarized space. With this type of territory, it develops unevenly; economic activity is concentrated in certain "centers" ("centers", "points", "poles" of growth) [5, 6, 7]. Thus, resources gravitate towards these centers of gravity; the territory of Russia is divided into the center and the periphery. 
The Siberian Federal District has a vast territory and a rich resource base of minerals. The district includes 10 regions. The territory of the Siberian Federal District is $25.47 \%$ of the territory of Russia, the population as of January 1, 2021 is about 17 million people. The population density as of January 1, 2021 is 3.9 people. per $1 \mathrm{~km} 2$ [1].

The economically active population is $51 \%$ of the total population of the Siberian Federal District, which is in line with the national average. A fifth of the working population is employed in industry, and $12 \%$ in agriculture. The district accounts for $9.6 \%$ of the GRP of the country's regions (data from 2020). In terms of predicted oil, natural gas and condensate resources, it ranks second in the Russian Federation after Western Siberia. According to expert estimates, up to half of all hydrocarbon resources in the eastern part of the country are concentrated here [3].

The development of the territory of the Siberian Federal District by information and telecommunication networks is a priority task for government bodies. However, the exception is some northern territories (adjacent to the Arctic zone) and areas with a large predominance of mountains, where the average population density is about 0.05 people. per $\mathrm{m} 2$, the development of such information and telecommunication networks territory is impractical.

\section{Research methodology}

The paper carries out an econometric analysis of the statistical data of Rosstat (Federal State Statistics Service), the collection "Regions of Russia" [1] in the direction of "Information and telecommunication networks" for the period from 2010 to 2018.

In the paper «Research of issues of connectivity of the regional space by information and communication technologies" the authors developed a model for calculating the coefficients of connectivity of the regional space [8]. For determining a level of spatial connectivity of the information and telecommunication networks territory, we use the criteria folding method. This method is used for multiobjective optimization problems. The additive convolution of criteria is used as a method for constructing an integral criterion that contains weighted sums of local criteria. The criteria have weighting coefficients of importance, determined by expert judgment, and an integral (rating) number.

For simplicity, each indicator has been designated with the letter $\mathrm{Q}$ and an ordinal number. Information and communication networks, according to the classification of Rosstat data [collection regions of Russia], include the following quantitative indicators:

- The proportion of the households with broadband Internet access in the total number of households $(\%)-\mathrm{Q} 1$.

- The proportion of the population using the Internet in the total population (\%)-Q2.

- The proportion of organizations using broadband Internet access in the total number of surveyed organizations (\%) - Q3.

- The number of connected user's mobile devices per 1000 of the population (at the end of the year), it is measured in pieces - Q4.

- The number of active broadband Internet users per 100 of the population (at the end of the year), fixed Internet units - Q5.

- The number of active broadband Internet users per 100 of the population (at the end of the year), mobile Internet units - Q6.

Model view for determining the level of connectivity of the regional space:

$$
C\left(Q_{i}\right)=\sum_{i=1}^{n} \alpha_{i} Q_{i}
$$


where the coefficient $\alpha_{\mathrm{i}}-\mathrm{a}$ weighting factor that determines the degree of influence of each criterion $Q_{i}$ for the final result, $Q_{i}-\mathrm{a}$ criterion presented as a statistical indicator for a certain time period. Weight coefficients $\alpha_{i}$ are chosen so that their sum is equal to one:

$$
\sum_{i=1}^{n} \alpha_{i}=1
$$

Using this model (1), we get the level of connectivity in percent for a specific region of the Siberian Federal District.

To calculate the indicators, an algorithm for automating the procedure for calculating statistical indicators in the "Python" software environment was proposed. Screenshot of the program code in Python in the Spyder programming environment with the displayed results by year (Fig. 1):

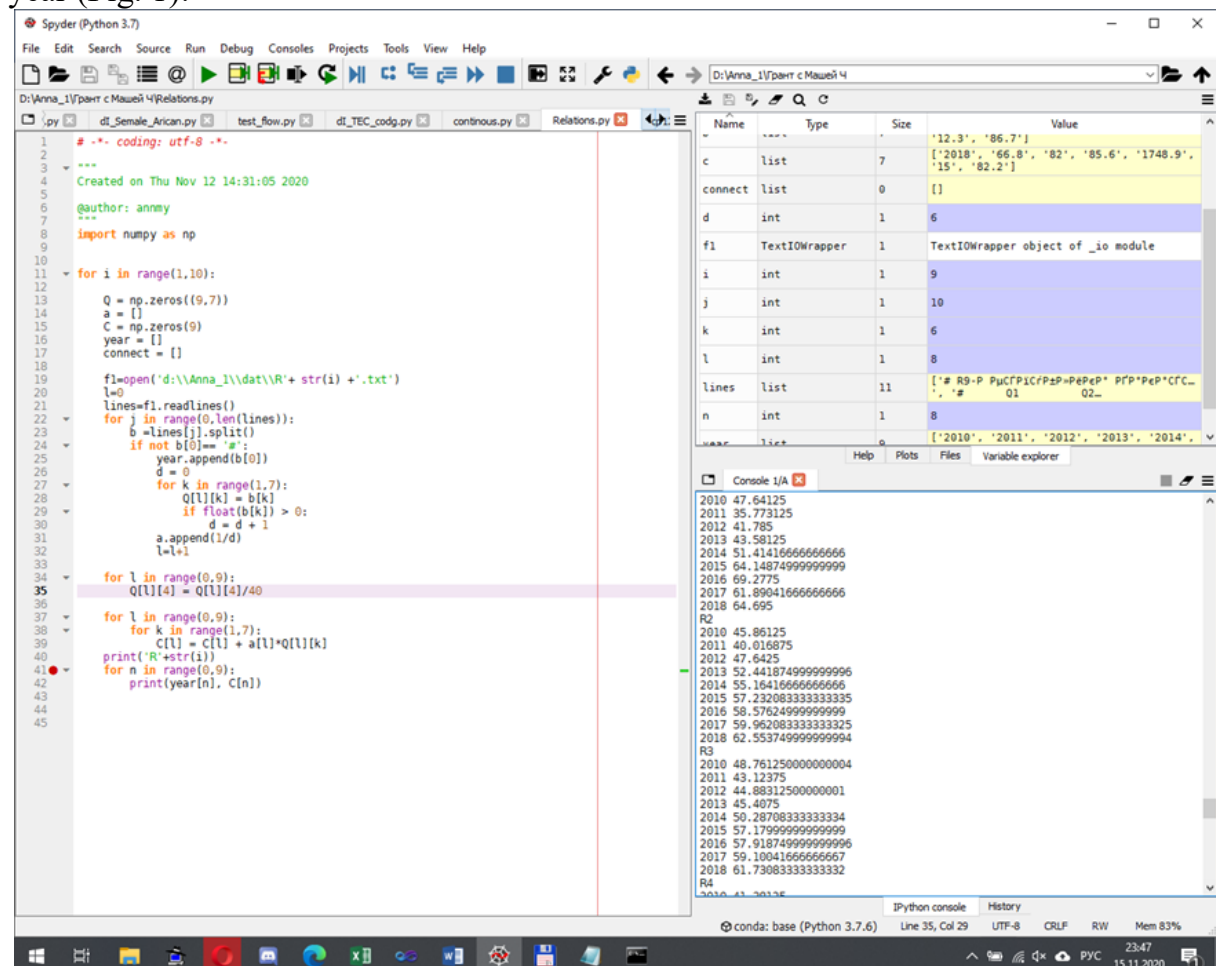

Fig 1. Program code in the "Python" language in the "Spyder" programming environment with applying authors model for calculating of the spatial connectivity with using statistical indicators "Information and telecommunication networks" from 2010 to 2018.

For ease of understanding, the following abbreviations have been used:

- R1 - Irkutsk region;

- R2- Krasnoyarsk Territory;

- R3- Tomsk region;

- R4 - Novosibirsk region;

- R5 - Omsk region;

- R6 - Altai Territory;

- R7 - Republic of Altai;

- R8-Kemerovo region;

- R9 - Republic of Khakassia;

- R10 - Republic of Tuva. 
The automation algorithm will make it possible to determine the level of development of information and telecommunication networks in each of the regions of the Siberian Federal District.

\section{Research results}

Further, the calculation of the determination of the connectivity indicators was carried out according to the mathematical model and algorithm developed by the authors in the "Python" environment in the period from 2010 to 2018. We collected statistics from the collection "Regions of Russia", found the average value of connectivity for each region. The results are shown in Table 1 .

Table 1. Determination of the developing level of information and telecommunication networks within the regions of Siberian Federal District

\begin{tabular}{|r|c|c|c|c|c|c|c|c|c|r|r|}
\hline & \multicolumn{9}{|c|}{ Year } & $\begin{array}{c}\text { Averag } \\
\text { evalues }\end{array}$ \\
\cline { 2 - 13 } & $\mathbf{2 0 1 0}$ & $\mathbf{2 0 1 1}$ & $\mathbf{2 0 1 2}$ & $\mathbf{2 0 1 3}$ & $\mathbf{2 0 1 4}$ & $\mathbf{2 0 1 5}$ & $\mathbf{2 0 1 6}$ & $\mathbf{2 0 1 7}$ & $\mathbf{2 0 1 8}$ & \\
\hline Name & \multicolumn{9}{|c|}{} & \multicolumn{9}{|c|}{} & \\
\hline R1 & 47.6 & 35.85 & 41.8 & 43.6 & 51.4 & 64.4 & 69.3 & 61.9 & 64.7 & $\mathbf{5 3 . 4}$ \\
\hline R2 & 45.9 & 40.0 & 47.6 & 52.4 & 55.2 & 57.2 & 58.6 & 59.9 & 62.5 & $\mathbf{5 3 . 0}$ \\
\hline R3 & 48.8 & 43.0 & 44.9 & 45.4 & 50.3 & 57.2 & 57.9 & 59.1 & 61.7 & $\mathbf{5 2 . 0}$ \\
\hline R4 & 41.4 & 44.0 & 49.7 & 52.5 & 58.3 & 58.8 & 58.3 & 63.4 & 68.4 & $\mathbf{5 5 . 0}$ \\
\hline R5 & 54.8 & 46.5 & 52.2 & 54.8 & 64.7 & 64.2 & 64.1 & 69.7 & 73.2 & $\mathbf{6 0 . 5}$ \\
\hline R6 & 42.4 & 41.2 & 46.9 & 50.6 & 52.7 & 55.9 & 54.5 & 59.5 & 62.7 & $\mathbf{5 1 . 8}$ \\
\hline R7 & 42.4 & 41.2 & 46.9 & 50.6 & 52.7 & 55.9 & 54.5 & 59.5 & 62.7 & $\mathbf{5 1 . 8}$ \\
\hline R8 & 52.3 & 41.2 & 46.5 & 48.1 & 52.5 & 54.5 & 55.9 & 58.9 & 61.6 & $\mathbf{5 2 . 4}$ \\
\hline R9 & 59.6 & 48.7 & 52.7 & 55.7 & 55.5 & 60.6 & 56.7 & 58.6 & 60.5 & $\mathbf{5 6 . 5}$ \\
\hline R10 & 28.5 & 37.9 & 42.6 & 46.03 & 43.5 & 46.4 & 46.2 & 52.9 & 55.3 & $\mathbf{4 4 . 4}$ \\
\hline
\end{tabular}

The last column shows the average value of the coefficients of connectivity of the regional space by information and telecommunication networks for each region of the Siberian Federal District. The results of the study are presented in table 2.

Table 2 . The value of the coefficients of connectivity of the regional space (spatial connectivity) by information and telecommunication networks of each of the regions of the Siberian Federal District

\begin{tabular}{|c|c|}
\hline Region name & $\begin{array}{c}\text { The value of the coefficient of } \\
\text { spatial connectivity of information } \\
\text { and telecommunication networks }\end{array}$ \\
\hline Irkutsk region & 53.4 \\
\hline Krasnoyarsk region & 53.0 \\
\hline Tomsk region & 52.0 \\
\hline Novosibirsk region & 55.0 \\
\hline Omsk region & 60.5 \\
\hline Altai region & 51.8 \\
\hline Altai Republic & 51.8 \\
\hline Kemerovo region & 52.4 \\
\hline The Republic of Khakassia & 56.5 \\
\hline Tyva Republic & 44.4 \\
\hline
\end{tabular}

It is proposed to introduce a numerical definition of the level of development of information and telecommunication networks in the territory of these regions. The resulting minimum value is 44.4 in the Republic of Tyva, the average value is 53.0 in the Krasnoyarsk region, and the maximum value is 60.5 in the Omsk Region. The value of the 
coefficients depends on the area covered by the information and telecommunication networks territory.

For example, the Krasnoyarsk region is one of the largest regions in terms of territory, it has vast northern territories, and therefore it has an average indicator in terms of the level of information and telecommunication networks development. Also the Omsk Region has an area of three slots less, and the information and telecommunication networks coverage area is larger. Another factor affecting the quality of information and telecommunication networks is the mountainous terrain, the Krasnoyarsk region, the Irkutsk region have a large number of mountains, which also affects the reception and distribution of communication signals across the territory.

\section{Discussion of the results}

The existing level of interaction between the regions of the Russian Federation does not fully meet the requirements of the formation of a single economic space. The European countries have more grounds to be considered a single country than individual regions within the borders of a single Russia. $[9,10]$. The study of the issues of measuring the quality of economic space, including the connectivity of the regional space (spatial connectivity) as an economic category, it is able to characterize each region in terms of the degree of development of one or another resource, in our case, information and telecommunication networks. The resulting mechanism for calculating the coefficients of connectivity of the regional information and telecommunication networks will be useful for drawing up passports of regions by government authorities, as well as for an annual survey of the territory (monitoring) by the Federal State Statistics Service.

\section{Conclusions}

The information and telecommunication networks are an important infrastructure complex. Thus, the study of the characteristics of the interconnectedness of the regional space and the development of models for its assessment can bring a significant contribution to solving the problems of determining the interconnectedness of the regional space. Some of the existing models for assessing the connectivity of the regional space consider the level of connectivity through qualitative indicators grouped according to a certain criterion; other models are in the form of mathematical models using statistical indicators. The model proposed by the authors will allow us to consider the connectivity of the regional space, taking into account the development of the information and telecommunication networks of a territory. The integral indicator developed by the authors has theoretical and practical significance. The theoretical significance of the proposed model lies in complementing the system for assessing the quality of economic space within the framework of the spatial approach. From a practical point of view, the model in the form of an integral indicator acts as a tool that can be used to monitor regional problems and situations or for an annual survey of the territory by the Federal State Statistics Services under a constituent entity of the Russian Federation.

The concept of spatial connectivity of the information and telecommunication networks is studied on the example of the Siberian Federal District. Analysed and grouped the existing static indicators from the collection "Regions of Russia" (the collection is published by the Federal State Statistics Service) in the direction of "information and telecommunication networks" for the period from 2010 to 2018. The author's mathematical model based on the criteria convolution method is proposed. 
To obtain the coefficients, an automation algorithm was written in Python in the Spyder programming environment with the output of the results for years. As a result, the coefficients of the level of development of information and telecommunication networks of each region of the Siberian Federal District were determined.

Research is supported by a grant from the President of the Russian Federation for young scientists candidates of sciences No. 075-15-2020-044/1 from 03/29/2021.

\section{References}

1. G. Granberg, Fundamentals of Regional Economics (2000)

2. Federal State Statistic Service Region of Russia: the main characteristics of the subjects of the Russian Federation (Moscow: Rostat Publ) (2019)

3. M. N. Chuvashova. Management of social and economic systems, 3, 19. (2021)

4. G. Polyakova A G, I. S. Simarova, Economy of the region. 2. (2014)

5. G. Polyakova A G, I. S. Simarova, State and municipal management issues. 3 (2014)

6. V. N. Ukrainskya, Regional studies, 5, 4. (2017)

7. N. V. Zubarevich, Russian economic journal ECO, 4, 478.(2014)

8. N. P. Goridko, R.M. Nizhegorodtsev, Economy of the region, 14, 1.(2018)

9. E. L. Plisetskiy, Regional economics: theory and practice. 11, 68. (2008)

10. M. N. Chuvashova, A. A. Mylnikova, A. K. Gorbacheva [et al.]. Phys. J., 042025 (2020) 